\title{
Population dynamics of Chaoborus flavicans and Daphnia spp.: effects on a zooplankton community in a volcanic eutrophic lake with naturally high metal concentrations (L. Monticchio Grande, Southern Italy)
}

\author{
Barbara LEONI* and Letizia GARIBALDI \\ Università degli Studi di Milano Bicocca, Dip. di Scienze dell'Ambiente e del Territorio, Piazza della Scienza 1, 20126 Milano, Italy \\ *e-mail corresponding author: barbara.leoni@unimib.it
}

\begin{abstract}
The response of Daphnia populations to invertebrate predators involves morphological or behavioural changes. Few studies suggest that contaminant aqueous metals, like $\mathrm{Cu}$ or $\mathrm{Ni}$ at environmentally relevant concentrations, interfere with invertebrate chemical communication systems, such as that which operates between Daphnia and Chaoborus. The objective of our study was to determine if this interference could be also observed in lakes naturally rich in dissolved metals, such as volcanic lake (Lago Grande di Monticchio). This study aimed to assess if natural dissolved metals (e.g., Fe, Mn and Sr) could impair the ability of Daphnia pulex and D. galeata $\times$ hyalina $\times$ cucullata 'complex' populations to respond to Chaoborus kairomones by producing morphological defenses against potential predation, and to understand how Chaoborus predation might affect zooplankton community composition and overall zooplankton density. The predator impact did not result in: i) any morphological changes; ii) any apparent shift in body size pattern of the prey population; iii) any shift in life history traits. Chaoborus accounted for high mortality rates in Cladocera and strongly reduced the chance of individuals to reach maturity. Moreover, highly significant negative correlations between abundance of dominant taxa of zooplankton and $\mathrm{C}$. flavicans were found. The last larval instars of $\mathrm{C}$. flavicans seem to reduce the number of crustaceans, particularly cladocerans and copepod adults and could play an important role in structuring zooplankton communities. Our results suggest that metal inhibition of defence strategies induction probably occurs along the signal transduction pathway in Lake Grande di Monticchio. Impairment of chemosensory response to predatory chemical cues may have widespread ecological consequences in aquatic systems. Chaoborus predation effects can greatly affect both zooplankton biomass and community composition, impact interactions at lower trophic levels and generate an ecological cascade leading to a rapid eutrophication.
\end{abstract}

Key words: predator-prey system, zooplankton, metal inhibition, volcanic lake

\section{INTRODUCTION}

Predation is one of the most important factors controlling the structure and dynamics of natural ecosystems (Wellborn et al. 1996; Van de Meutter et al. 2005). Invertebrate predators, such as Chaoborus (Diptera) larvae, play a major role in structuring zooplankton communities in lakes by directly limiting prey populations (Hanazato \& Yasuno 1989; Hanazato 1990) and altering the dynamics, size and structure of prey populations (Neill 1981; Mumm 1997; Riccardi et al. 2002). The 'Chaoborus-Daphnia / predator-prey' system is very well studied. Daphnia are known to respond to the presence of predators by changing their life history, morphology and behaviour (reviewed in Tollrian \& Dodson 1999). The induction of an antipredator defence in Daphnia is thought to be mediated by the presence of predatory cues: kairomones, which are thought to be a low molecular weight, nonolefinic hydroxyl-carboxylic acid (Tollrian \& von Elert 1994). In the presence of Chaoborus kairomones, cladocerans reproduce later at a larger size, and they produce larger but fewer daphniids (Jeyasingh \& Weider 2005). As suggested by Lynch (1980), there is a trade-off between energy allocated for somatic growth and energy allocated for reproduction.
Moreover, kairomones of invertebrate predators are known to induce elongation of tail spines, enlarged helmet crests or the development of neck teeth in Daphnia spp. (Parejko 1991; Spitze 1992; Black 1993; Repka et al. 1995) as a defence mechanism that makes the handling of prey more difficult (Caramujo \& Boavida 2000) and/or increases the prey's escape ability (Mort 1986; Swift 1992).

Morphological adaptations may prevent local extinction of Daphnia by Chaoborus. Induction of such morphological adaptations requires Daphnia to be able to detect the kairomones. Several studies have shown that metals can affect chemoreception in fish (Hansen et al. 1999; Beyers \& Farmer 2001). Hunter \& Pyle (2004) demonstrated experimentally that Chaoborus kairomones neck tooth induction in Daphnia pulex was reduced in the presence of the dissolved metals $\mathrm{Cu}$ and $\mathrm{Ni}$ at environmentally relevant concentrations, whereas no significant effects were observed on body length or brood size.

This study aimed to assess the 'Chaoborus-zooplankton / predator-prey' system in populations inhabiting a lake naturally rich in dissolved metals, and to understand how Chaoborus predation might affect zooplankton community composition and overall zoo- 


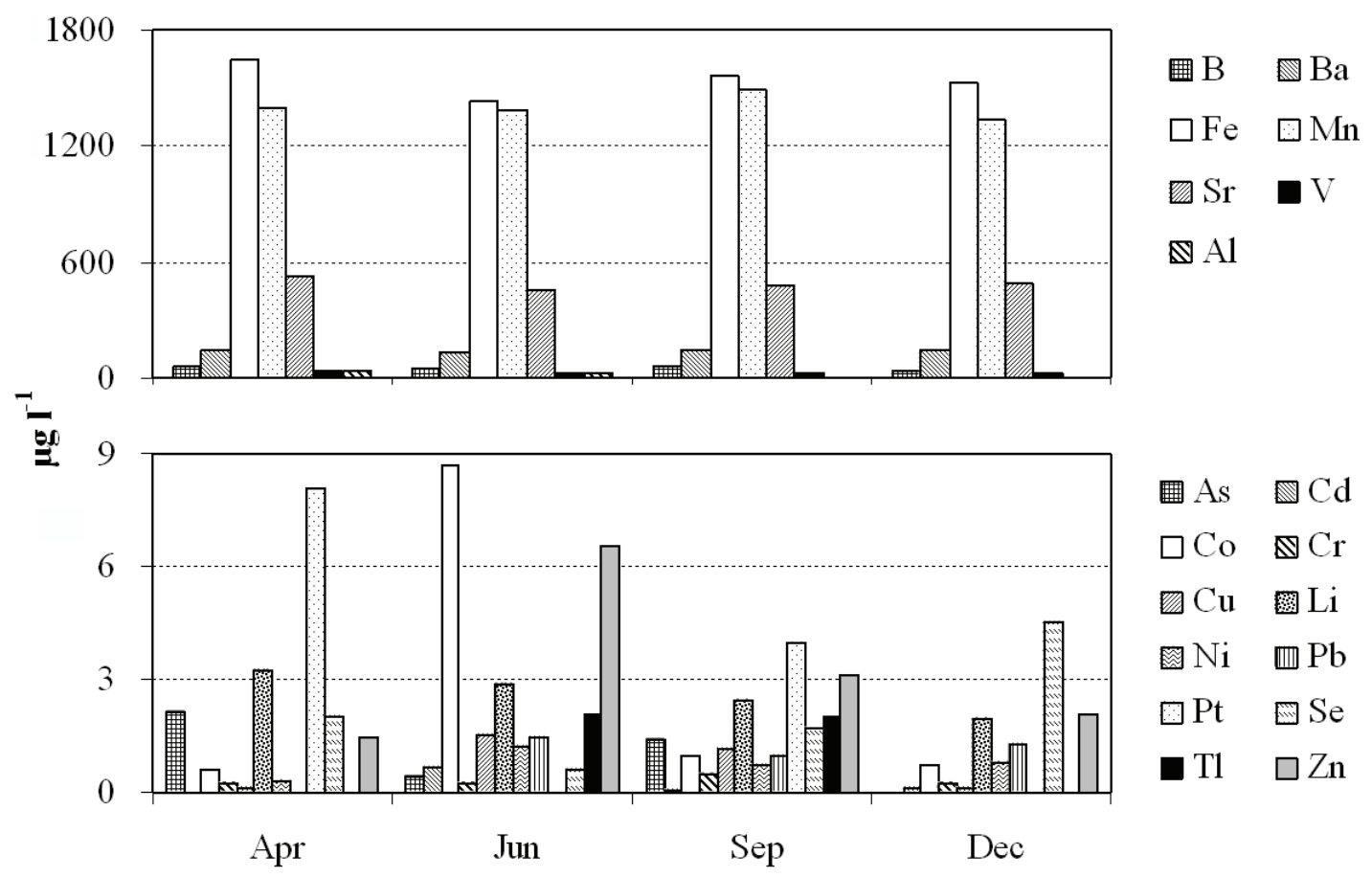

Fig. 1. Seasonal changes in mean concentrations of dissolved metals in the water column of MG Lake in 2005.

plankton density. We hypothesized that natural dissolved metals could impair the ability of some zooplanktonic taxa to respond to Chaoborus kairomones, and may therefore lead to the failure of individuals to produce life history and morphological changes as a defence against potential predation. In particular, we estimated the effects of dissolved metals on the Chaoborus-Daphnia system, one of the best-known examples of inducible defences and an important trophic link in pelagic food webs (Boeing et al. 2005). To this end we analysed the population dynamic of Chaoborus flavicans and the size structure and morphology traits of Daphnia pulex and D. galeata $\times$ hyalina $\times$ cucullata 'complex' and in a volcanic lake naturally rich in dissolved metals (Lake Grande di Monticchio).

\subsection{Study site}

Lake Grande di Monticchio (hereafter referred to as MG Lake) is the larger of two adjacent maar lakes, lakes of Monticchio $\left(650 \mathrm{~m}\right.$ a.s.l., $\left.40^{\circ} 55^{\prime} \mathrm{N}, 15^{\circ} 35^{\prime} \mathrm{E}\right)$, within a caldera on the western slopes of the Mount Vulture in the Basilicata region of southern Italy. Despite the name Lago Grande (Large Lake), it is a small $\left(0.41 \mathrm{~km}^{2}\right)$ and relatively deep lake (maximum depth $=36.3 \mathrm{~m}$; mean depth $=8.5 \mathrm{~m}$ ). It has a small drainage area $\left(3.9 \mathrm{~km}^{2}\right)$ and its most important water sources are represented by internal springs, precipitation, runoff and water coming from Lago Piccolo di Monticchio (Small Lake), a small oligotrophic basin connected to Lago Grande by a short stream (length: $216 \mathrm{~m}$, flow: $50 \mathrm{~L} \mathrm{~s}^{-1}$ ).
MG Lake is a meromictic lake, characterised by high concentrations of ions in deeper layers (the monimolimnion). Among the consequences of stable stratification of lake waters is that the monimolimnion (from 20 to $38 \mathrm{~m}$ ) becomes depleted of oxygen (less than $1 \mathrm{mg}$ $\left.\mathrm{L}^{-1}\right)$. However, MG Lake has two separate areas differing in morphometry. A large area is relatively shallow (maximum depth $12 \mathrm{~m}$ ) and rich with macroscopic submersed vegetation, and the water is mixed completely twice a year. The oxygen concentration remains fairly high for a few months, but stratification forms, during summer, an oxygen profile representing a clinograde, with a chemocline occurring at a depth of $5 \mathrm{~m}$.

Chemical data show a situation between eutrophic and hypereutrophic conditions, with a total P concentration frequently exceeding $60 \mu \mathrm{g} \mathrm{L}^{-1}$ and a Secchi disk depth in summer of about $70 \mathrm{~cm}$. The $\mathrm{pH}$ profile decreases from the surface to the bottom, ranging from 9.1 to 5.9. This $\mathrm{pH}$ gradient exists because volcanic spring waters are rich in $\mathrm{CO}_{2}$ and $\mathrm{SO}_{2}$ escapes from the residual volcanic activity. The concentration of dissolved metals in the water is very high and is due to emissions of mineral water from submerged springs, resulting in elevated concentrations of iron, manganese and strontium (Fig. 1).

The most common aquatic plants in the lake are Typha latifolia, Phragmites spp., Ceratophyllum spp. and Nymphaea alba. The fish assemblage is dominated by cyprinids, with tench (Tinca tinca), common carp (Cyprinus carpio), rudd (Scardinius erythrophthalmus) perch (Perca fluviatilis) representing the major fish species in MG Lake. Larvae of Chaoborus flavicans 
(Meigen) are found in the lake. This species is widely distributed in the holarctic region, has four larvae instars, and is usually univoltine. It inhabits eutrophic lakes and is adapted to coexist with dense fish populations, which has usually been explained by its ability to avoid predation by vertical migrations (McQueen et al. 1999; Gliwicz et al. 2006). Some studies also suggest that the ability to disperse horizontally when faced with food shortage, and the flexible utilization of benthic and limnetic habitats, may facilitate the maintenance of large populations (Liljendahl-Nurminen et al. 2002).

\section{METHODS}

Zooplankton and Chaoborus larval samples were taken monthly in 2005 using Wisconsin nets $(40 \mathrm{~cm}$ in diameter, 200 and $60 \mu \mathrm{m}$ mesh) hauled vertically from a $10-\mathrm{m}$ depth to the surface. The use of this type of net and mesh sizes efficiently captures zooplankton like Rotifera, Cladocera and Copepoda, including copepodites and nauplii, and occasional plankton organisms such as dipteran larvae. Each sample was obtained by pooling three replicate hauls collected in correspondence at the deepest point. The volume of water filtered was determined indirectly, assuming that the net filters the whole volume of the water column. Zooplankton and Chaoborus larvae were preserved for analysis in a $4 \%$ buffered sucrose-formalin solution. In the laboratory, identification and counts of adult crustaceans and rotifers were made mostly to the species level, while nauplii and copepodite stages (C1-C5) were categorized to different suborders (Cyclopoida and Calanoida). Taxon identification was performed with reference to Ruttner-Kolisko (1974), Margaritora (1983), Dahms \& Fernando (1993), Nogrady et al. (1993) and Dussart \& Defaye (1995).

Measurements of total length (length from the anterior end of the carapace to the end of the tailspine), mean length (length from the anterior end of the carapace to the base of the tailspine) and height were performed only on individuals of the Daphnia galeata $\times$ hyalina $\times$ cucullata 'complex' using a PC provided with image analysis software. Pictures of adult females were taken using a digital camera (Olympus Camedia C7070) installed on a microscope (Wild Leitz GMBH). The number of individuals analysed varied among samples (from 20 to 100) and depended on the density of the population. Sizes at maturity for individuals of the Daphnia 'complex' were determined according by Caramujo et al. 1997.

The number of Chaoborus larvae and relative abundance of each developmental stage were estimated microscopically for the whole sample. The head capsule length of all larvae for each instar was measured using a PC, similar to the system used for Daphnia individuals. The mouth width was estimated as approximately half of the head capsule length (Mumm \& Sell 1995).
Spearman's rank correlation coefficient was calculated to measure the correlation between Chaoborus abundance and more representative taxa of zooplankton density and the correlation between male proportions with changes in Chaoborus densities. Spearman's analysis was also applied to detect a possible effect of sizeselective predation on the Daphnia 'complex'. Body length, total length and height of more than 80 individuals per sampling date were measured and the analysis was performed using mean total length, mean length, mean height (and their standard deviation).

Performing many tests on the same set of data may have resulted in an increased risk of type I statistical error, i.e., the rejection of the null hypothesis due to mere chance. To solve this problem Bonferroni correction is usually applied, but a strict application of this method strongly reduces the power of statistical test. A new approach that avoids such problem is to adopt False Discovery Rate (FDR) correction (Benjamini \& Hochberg 1995; Garcia 2003; Verhoeven et al. 2005). However, in the absence of a general consensus for how to apply correction methods in multiple tests (see Nakagawa 2004), we decided to adopt the following approach. We will present uncorrected $P$-values and, for simplicity, will report values lower than 0.05 as significant. However, we will also apply FDR correction and report the tests that were significant according to this procedure. In the discussion, we will warn the reader that some of the statistical tests reported as significant may reflect type I statistical errors.

\section{RESULTS}

\subsection{Zooplankton dynamics}

In the zooplankton assemblage of MG Lake we found 15 taxa of Rotifera, 6 taxa of Cladocera and 1 taxon belonging to the Copepoda. The maximum density of zooplankton was recorded in February (146581 ind $\mathrm{m}^{-3}$ ) and a progressive decrease was observed during spring and summer, with values subsequently declining to reach a minimum in July (12941 ind $\mathrm{m}^{-3}$ ), followed by a small increase in autumn $\left(76775\right.$ ind $\left.\mathrm{m}^{-3}\right)$. The community was always dominated by Rotifera in terms of abundance: $43 \%$ in February; $95 \%$ in July, and $85 \%$ in December. Copepoda relative abundance varied considerably, ranging from $35 \%$ in February to $3 \%$ in June, whereas the Cladocera showed a great density percentage $(25 \%)$ from February to May that decreased during June $(1 \%)$. Polyarthra was the dominant genus in the lake from April to August, while Keratella cochlearis was the dominant species in autumn and winter. Other taxa such as Keratella quadrata, Brachionus spp., Tricocherca spp. and Synchaeta spp. showed exiguous and sporadic populations (Fig. 2a). In the lake, Copepoda were only represented by Cyclops lacustris. Cyclopoids showed a conspicuous density in February (52038 ind $\mathrm{m}^{-3}$ ) when the over-wintered adults were prevalent. From May to October, the copepod commu- 

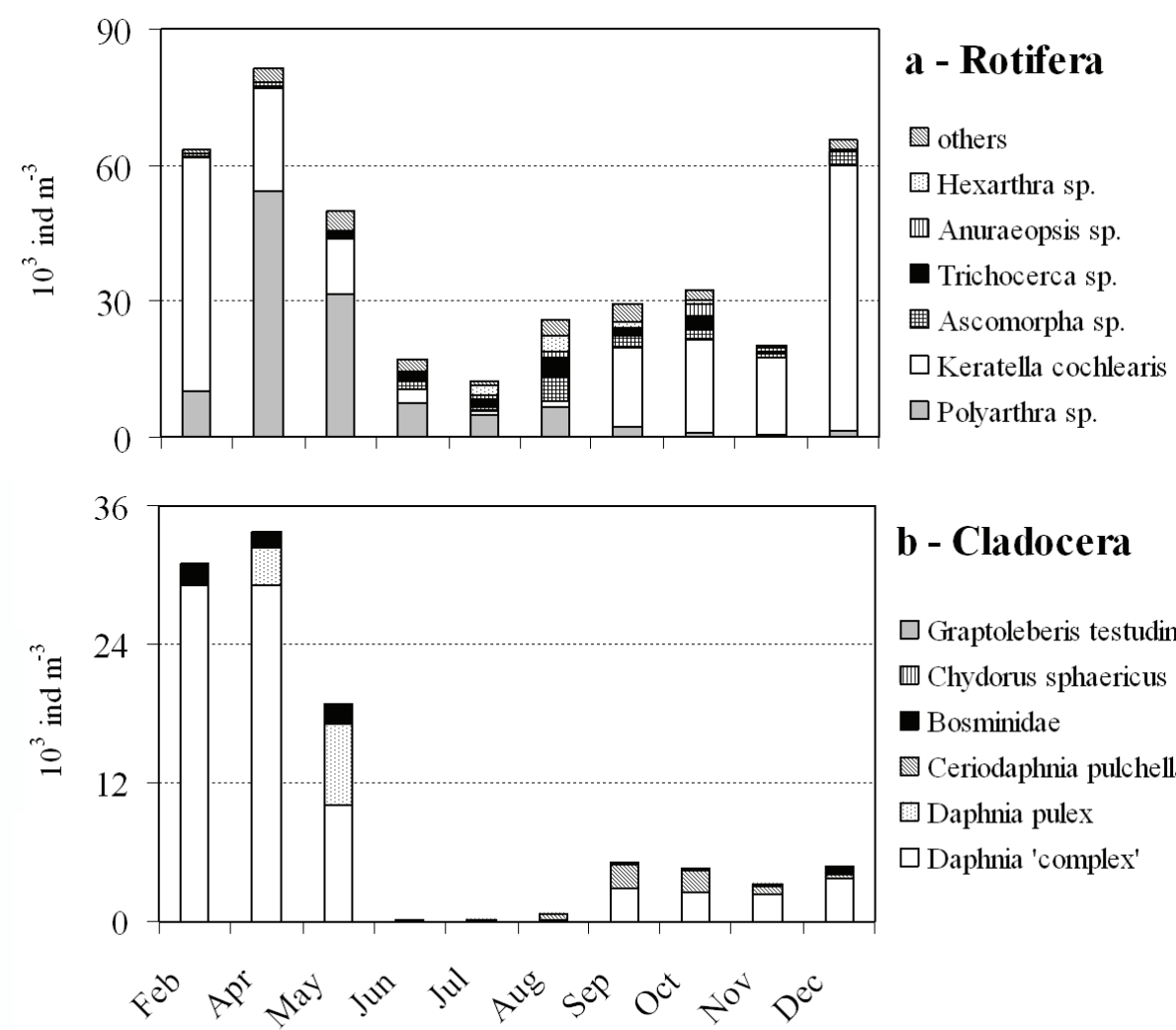

b - Cladocera

$\square$ Graptoleberis testudinaria

四 Chydorus sphaericus

Bosminidae

$\mathbb{Q}$ Ceriodaphnia pulchella

Daphnia pulex

$\square$ Daphnia 'complex'

Fig. 2. Population dynamics of Rotifera (a) and Cladocera (b). Others: Brachionus urceolaris, Ploesoma sp., Filinia longiseta, Lecane luna, Synchaeta sp., Euchlanis dilatata, Monommata longiseta, Keratella quadrata and Asplanchna priodonta.

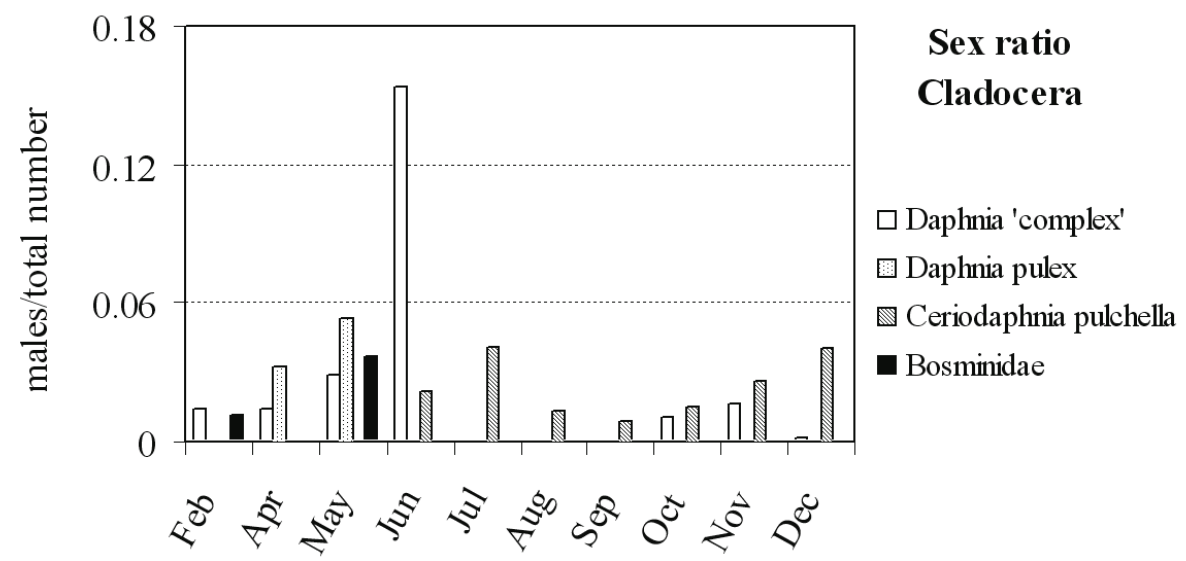

Fig. 3. Seasonal variation in sex ratio (male number $v s$ total number) of dominant taxa of Cladocera.

nity was dominated in abundance by nauplii and copepodites (ranging from 60 to $80 \%$ ). Cladocerans had their maximum development in April, and thereafter nearly all of the cladoceran species decreased dramatically. In September, only the small species Ceriodaphnia pulchella and members of the Daphnia 'complex' showed a slight increase in abundance. A peak of Bosminidae and Daphnia pulex was observed during late-winter and spring, but $D$. pulex declined after June and did not recover. Among the Cladocera, members of the Daphnia galeata $\mathrm{x}$ hyalina $\mathrm{x}$ cucullata 'species complex' (reviewed in Schwenk \& Spaak 1997) dominated the community (Fig. 2b).

Cladoceran reproduction in $\mathrm{MG}$ Lake involved cyclical parthenogenesis, and the parthenogenetic phase always coexisted with an amphigonic phase. Males and ephippial females of nearly all taxa occurred in the lake (Fig. 3). The production of diapausing eggs occurred earlier in the year in Daphnia spp. and Bosminidae (from February). Males of C. pulchella, a warm stenotherm species, occurred from June to December. 

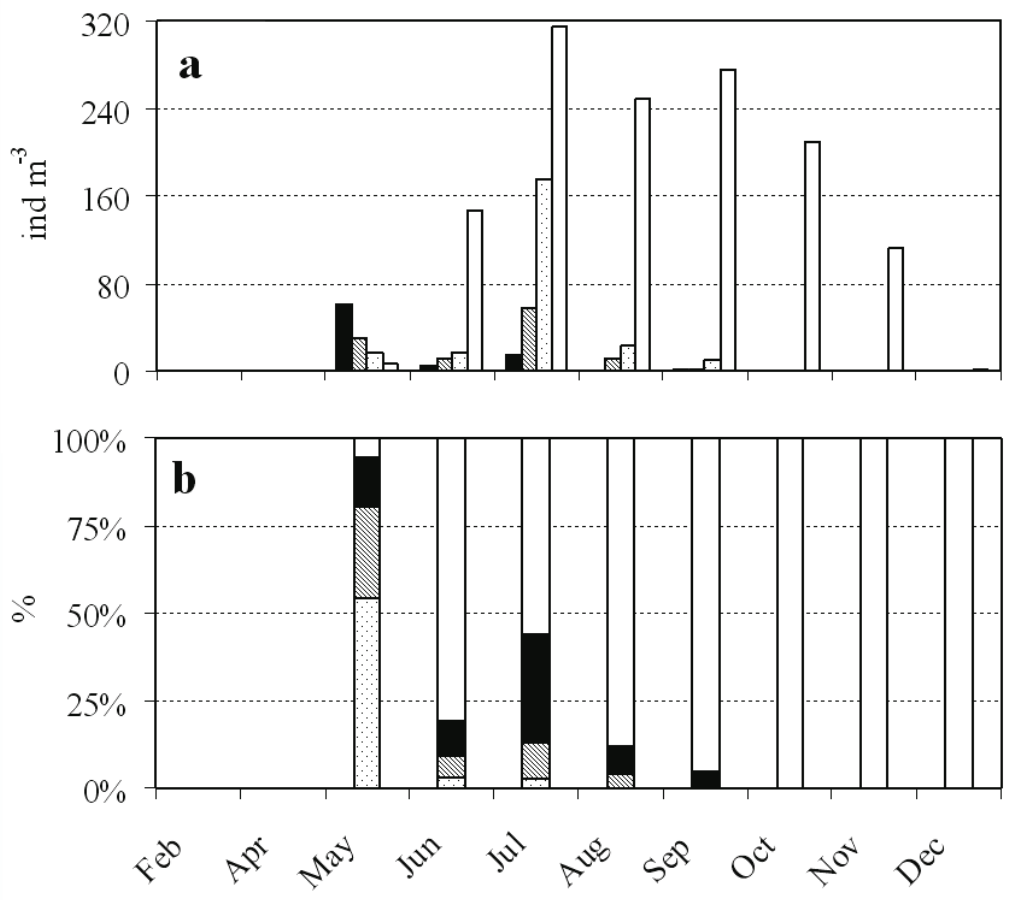

instars: $\square$ I $\mathbb{\text { II }} \square$ III $\square$ IV

Fig. 4. Seasonal variation in the density (a) and in the percentage (b) of the larval instars (I, II, III, IV) of Chaoborus flavicans from February to December 2005.

\subsection{Chaoborus flavicans larval dynamics}

Chaoborus flavicans larvae were not encountered in plankton samples in early spring. They first appeared in the water column in May, sharply increased in summer, and were still present in December. Higher fractions (about $60 \%$ of total instar larvae) of first instar larvae in the lake during May suggest that this may have been caused by stronger recruitment through Chaoborus eggs laid on the water surface (Fig. 4). The abundance of later instars (III and IV) sharply increased from June ( $80 \%$ of all instars) to October when only 4 th instar larvae were present. The abundance ( \pm S.D.) of larvae in the lake from May to July ranged from $113.6 \pm 4.5$ to $570 \pm 124$ ind $\mathrm{m}^{-3}$ and decreased in September, probably due to pupation and adult emergence but also likely due to predation by planktivorous fish (unfortunately, no data is available about ichthyofauna in MG Lake). The average mouth width of IV instar larvae varied from 363 to $628 \mu \mathrm{m}$ (mean $580 \mu \mathrm{m} \pm$ S.D. 39.3).

\subsection{Relationships between zooplankton and $\mathrm{C}$. flavicans}

Spearman's rank correlation analysis was used to estimate the relationships between metazooplankton and its possible predator. Nine out of the 36 correlation tests, performed for separate larval instars of Chaoborus (I, II, III and IV), were significant at the $P<0.05$ level
(Tab. 1). All significant correlations between the abundance of more representative taxa of zooplankton and $C$. flavicans were negative and interested both small (e.g., Bosminidae) and large (e.g., D. pulex) cladocerans, adult copepods and rotifer species. Eight of the nine tests that showed a significant correlations involved III and IV larval instars of $C$. flavicans. Four tests of Spearman's correlation, including Daphnia 'complex', Bosminidae and $K$. cochlearis, were still significant after False Discovery Rate (FDR) correction (Tab. 1).

Tab. 1. Spearman's rank correlation analysis between the abundance of more representative taxa of zooplankton and their predator. Analysis was performed for separate larval instars of Chaoborus (I, II, III and IV). Values in bold are significant, those that are still significant after FDR correction are underlined. Superscript letters indicate the significance level: ${ }^{\mathbf{a}}$ : $P \leq 0.001$; ${ }^{\mathbf{b}}$ : $0.001<P \leq 0.005$; ${ }^{\mathbf{c}}$ : 0.005 $<P \leq 0.01$; ${ }^{\text {d. }:} 0.01<P<0.05$.

\begin{tabular}{lcccc}
\hline & \multicolumn{4}{c}{ Chaoborus flavicans (larvae instars) } \\
\cline { 2 - 5 } & $\mathrm{I}$ & $\mathrm{II}$ & $\mathrm{III}$ & $\mathrm{IV}$ \\
\hline Daphnia 'complex' & -0.307 & -0.545 & $\mathbf{- 0 . 6 7 9}$ & $\mathbf{\mathbf { - 0 . 8 0 2 } ^ { \mathbf { b } }}$ \\
Daphnia pulex & 0.277 & 0.069 & -0.095 & $\mathbf{- 0 . 6 5 7}^{\mathbf{d}}$ \\
Ceriodaphnia pulchella & -0.228 & -0.144 & -0.033 & 0.646 \\
Bosminidae & -0.205 & -0.506 & $\mathbf{- 0 . 6 7 9}$ & $\mathbf{- 0 . 8 2 1}^{\mathbf{b}}$ \\
Cyclops lacustris -adults & -0.533 & -0.506 & -0.511 & $\mathbf{- 0 . 7 5 4}^{\mathbf{c}}$ \\
Cyclops lacustris - nauplii & -0.092 & -0.127 & -0.208 & -0.208 \\
Keratella cochlearis & -0.601 & $\mathbf{- 0 . 8 5 6}$ & $\mathbf{- 0 . 8 9 9}$ & $\mathbf{- 0 . 7 1 7}$ \\
Polyarthra sp. & 0.204 & 0.285 & 0.213 & -0.432 \\
Trichocerca sp. & 0.300 & 0.597 & 0.679 & 0.790 \\
\hline
\end{tabular}


The carapace height of Daphnia 'complex' adult females ranged from 360 to $650 \mu \mathrm{m}$ (mean $518 \mu \mathrm{m} \pm$ S.D. 130) and total length ranged from 870 to $1300 \mu \mathrm{m}$ (mean $1003 \mu \mathrm{m} \pm$ S.D. 160). The carapace height of Daphnia pulex ranged from 455 to $1243 \mu \mathrm{m}$ (mean 980 $\mu \mathrm{m} \pm$ S.D. 233) and total length ranged from 1310 to $2120 \mu \mathrm{m}$ (mean $1561 \mu \mathrm{m} \pm$ S.D. 220). Adults of both Daphnia taxa were above the size range for Chaoborus predation (see Results: Chaoborus larval dynamics). However, D. pulex individuals were bigger than those of the Daphnia 'complex' and could therefore be expected to be less vulnerable at a given developmental stage (Sell 2006).

No Daphnia spp. collected during the presence of $C$. flavicans in the water column showed a helmet, neck teeth, or other morphological changes.

Spearman's correlation analysis was also applied to detect a possible effect of size-selective predation on the Daphnia 'complex'. The correlation was calculated to measure the intensity of the association between chaoborid density and body length, total length and height. No significant correlations were found between dimensions of adult females and abundance of Chaoborus (Tab. 2, see also Fig. 5).

Tab. 2. Spearman's correlation coefficients correlating morphological metrics of adult females of Daphnia 'complex' with densities of III and IV larval instars of $C$. flavicans. No significant correlations were found. Analysis was performed on more than 80 individuals per sample (see Methods). Mean total length: length from the anterior end of the carapace to the end of the tailspine; mean length: length from the anterior end of the carapace to the base of the tailspine; S.D. standard deviation.

\begin{tabular}{lcc}
\hline & \multicolumn{2}{c}{ Chaoborus flavicans (larvae instars) } \\
\cline { 2 - 3 } Daphnia 'complex' & III & IV \\
\hline mean length & 0.327 & -0.455 \\
mean total length & 0.764 & 0.084 \\
mean height & 0.096 & -0.711 \\
S.D. of mean length & 0.546 & -0.024 \\
S.D. of mean total length & 0.327 & 0.132 \\
S.D. of mean height & 0.627 & 0.263 \\
\hline
\end{tabular}

Spearman's rank correlation analysis was used to estimate the relationships between cladocerans males and Chaoborus. Two out of the 16 correlation tests, performed for separate larval instars of Chaoborus (I, II, III and IV), were significant at the $P<0.05$ level (Tab. 3). Significant correlations were negative and involved Daphnia 'complex' males and III and IV larval instars of C. flavicans, one test was still significant after False Discovery Rate (FDR) correction (Tab. 3).

\section{DISCUSSION AND CONCLUSIONS}

The zooplankton features of MG Lake are typical of eutrophic lakes. An ecosystem generally becomes poor at high trophic levels (Kira 1993) with few species and a low structural complexity. A small number of taxa, few dominant species, and a high share of rotifers in the zooplankton are characteristic of MG Lake. Among the copepods, juveniles (nauplii and copepodites) dominate. In eutrophic water bodies, the life time of dominant species is short and young individuals prevail, while the adults are strongly decimated by predators (Ponyi \& Zankai 1982; Nicholls \& Tudorancea 2001). Metazooplankters inhabit mainly the epilimnion and metalimnion, where they find suitable living conditions. The anoxic hypolimnion does not qualify as a habitat for many zooplankters. This unsuitable zone expands during the process of eutrophication. The main factors controlling the abundance of chaoborid larvae seem to be stratification and the degree of the hypolimnetic oxygen deficit; the highest biomass of these dipterans is often found in eutrophic conditions, in which oxygen depletion is most common (Sæther 1997; LiljendahlNurminen et al. 2002). Co-occurrence of chaoborids with fish is confined to species that conduct diel vertical migrations, like C. flavicans (von Ende 1978; Sutor et al. 2001). The abundance of Chaoborus larvae in MG Lake is low when compared to the data of other studies (Mumm 1997). Since all samples were taken at a fixed depth $(10 \mathrm{~m}$ ) and time (circa 10:00 a.m.), the abundance of invertebrate predators may have been underestimated in some cases. Nevertheless, a theoretical model developed by Riessen (1992) predicts that Chaoborus densities $>0.5$ ind $\mathrm{L}^{-1}$ can have a significant impact on Daphnia populations, and several studies have shown that Chaoborus at moderate density causes a reduction in the density of zooplankton communities (e.g., Vanni 1988; Hanazato \& Yasuno 1989; Riccardi et al. 2002). Chaoborus can be more selective only if prey are abundant, choosing organisms that are easier to ingest based on size, shape or nutritive value (Pastorok 1981), but when food was scarce, as in MG lake, prey were attacked indiscriminately (Pastorok 1981; Riessen 1992).

Tab. 3. Spearman's rank correlation analysis between the abundance of cladocerans males and larval instars of Chaoborus (I, II, III and IV). Values in bold are significant, those that are still significant after FDR correction are underlined. Superscript letters indicate the significance level: ${ }^{\text {a }: ~} P \leq 0.001 ;{ }^{\mathbf{d}}$ : $0.01<P<0.05$.

\begin{tabular}{lcccc} 
& \multicolumn{4}{c}{ Chaoborus flavicans (larvae instars) } \\
\cline { 2 - 5 } & I & II & III & IV \\
\hline Daphnia 'complex' & -0.305 & -0.560 & $\mathbf{- 0 . 7 0 2}^{\mathbf{d}}$ & $\frac{\mathbf{- 0 . 8 8 9}}{-0.456}$ \\
Daphnia pulex & 0.307 & 0.148 & -0.055 & -0.537 \\
Ceriodaphnia pulchella & -0.302 & -0.264 & -0.171 & 0.537 \\
Bosminidae & 0.307 & 0.148 & -0.055 & -0.456 \\
\hline
\end{tabular}

Correlation analyses indicated that the strong decrease in zooplankton abundance in June and July was likely due to an increased mortality by predation. Highly significant negative correlations between abundance of dominant taxa of zooplankton and C. flavicans were found. The third and fourth larval instars of $C$. flavicans seem to significantly reduce the number of 


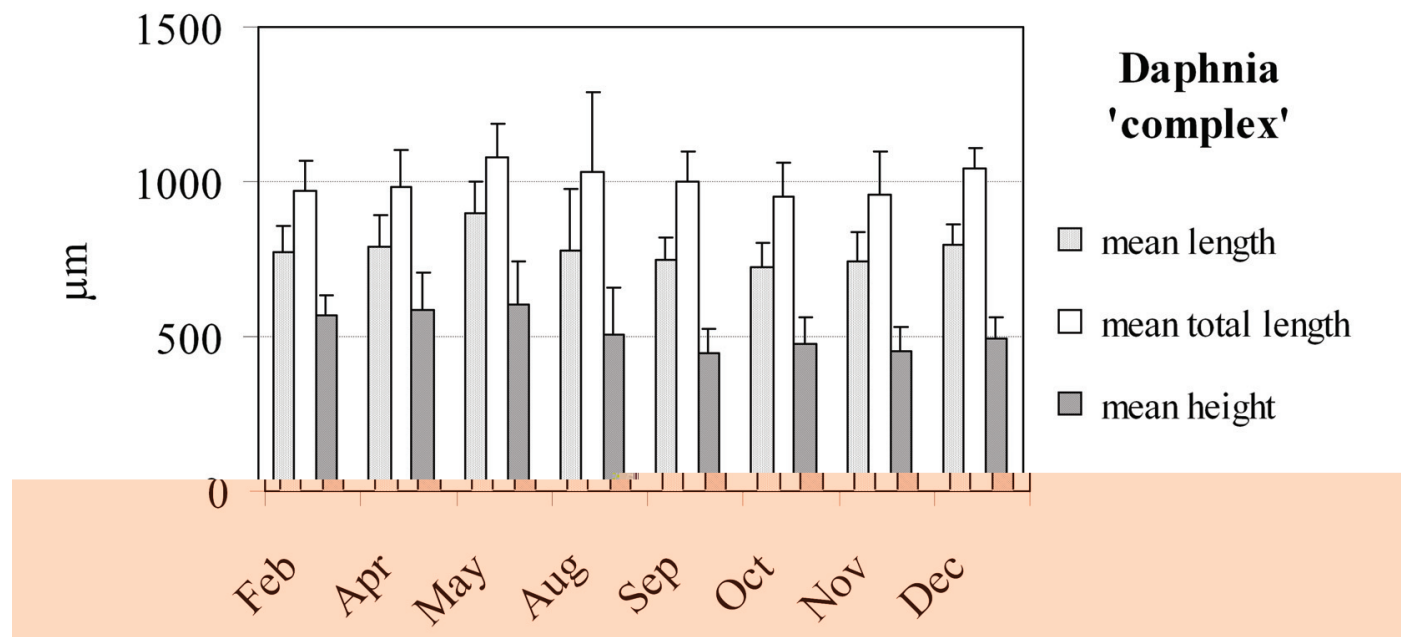

Fig. 5. Seasonal variation of morphological metrics of adult females of Daphnia 'complex' (mean value + S.D.). Analysis was performed on more than 80 individuals per date (see Methods). Total length: length from the anterior end of the carapace to the end of the tailspine; length: length from the anterior end of the carapace to the base of the tailspine.

crustaceans, particularly cladocerans and copepod adults and could play an important role in structuring zooplankton communities. We are therefore confident that the results were not biased. It must be emphasized that we ran several statistical tests and we consequently increased the risk of incurring type I statistical errors. Statistical tests may thus have led to erroneous rejection of the null hypothesis by pure chance in some cases. However, five correlation remained significant also after correcting the results of False Discovery Rate (FDR) procedure.

The hypothesis of a significant Chaoborus impact on zooplankton seems to be corroborated by the low density of adults in the populations; in fact, the maximum peak in egg and juvenile production observed in May seems not to have resulted in an increase in the number of adults. The presence of Chaoborus strongly reduces the chances of individuals reaching maturity (Sell 2000, 2006). A slight increase of the total population density should have been observed in August due to the absence of a high predation rate.

Evolution towards larger body size is expected to occur in Daphnia populations exposed to chaoborid predation (Black \& Dodson 1990; Stibor 1992). The Daphnia 'complex' of MG Lake don't show an increase in adult body size that is clearly related to size-selective predation (Fig. 5). Similarly, the high predation pressure did not result in morphological changes (e.g., neck teeth and tail spines).

Populations of cyclically parthenogenetic taxa reproduce asexually until unfavourable conditions arise (e.g., Gyllström \& Hansson 2004). Under unfavourable conditions, males are produced parthenogenetically and then sexual females produce haploid eggs that are fertilized by these males, resulting in 'resting eggs' that are able to withstand extreme situations and that hatch upon the resumption of favourable conditions. The switch to sexual reproduction appears to be related to a deterioration in the environment due to over-crowding, reduced food, a change in temperature and photoperiod (Stross 1971; Korpelainen 1992; Spaak 1995; Deng 1996; Innes \& Singleton 2000), or to predation (Nielsen et al. 2000; Cousyn et al. 2001).

If resting-egg production is the result of long-term adaptation to intense predation by Chaoborus, it is expected that males appear with an increase of dipteran density, while no significant positive correlations were found between male proportions and abundance of Chaoborus (Tab. 3). Since parthenogenic and amphigonic reproductions coexist throughout the year in MG Lake, another stressor factor probably exists and affects the populations over multiple years.

Overall, it seems that despite the apparent impact of Chaoborus on zooplankton in MG Lake no anti-predator strategies are developed. This failure to respond to changes in predation pressure might be related to an incapacity of prey to reliably detect chemical signals distributed by predators. Hunter \& Pyle (2004) demonstrated that the chemical communication system between Chaoborus spp. and D. pulex was impaired by environmentally relevant concentrations of metals $(\mathrm{Cu}$ and $\mathrm{Ni}$ ). The molecular mechanism that underlies chemoreception in invertebrates has been investigated only in Caenorhabditis elegans and Drosophila melanogaster and is not well understood in other invertebrate species (Krieger \& Breer 1999). Metals may interfere with some process along the signal transduction pathway from kairomone reception to the production of morphological change, and elevated concentrations of $\mathrm{Cu}$ and $\mathrm{Ni}$ may alter the chemistry of kairomones or out-compete kairomone molecules at kairomone receptor sites (Hunter \& Pyle 2004). At present, the mechanism of metal impairment of chemosensory function in Chaoborus-Daphnia predator-prey system 
remains unknown and warrants further investigation (Hunter \& Pyle 2004), and involves a system in which emissions of mineral water from submerged springs result in elevated metal concentrations.

The concentration of dissolved metals in MG Lake is very high: mean concentrations of iron and manganese exceed $1200 \mu \mathrm{g} \mathrm{L}^{-1}$ and those of strontium reach $500 \mu \mathrm{g} \mathrm{L}{ }^{-1}$ (see Fig. 1). We are not aware of any studies detailing any adverse effects of these dissolved metals on prey-predator systems; however, an influence cannot be excluded and their presence may interfere with the chemical communication system between Chaoborus and cladocerans. Larvae of $C$. flavicans seemed to topdown control the densities of zooplankton in MG Lake. Zooplankton organisms apparently fail to evolve effective strategies to minimise the risk of predation in this metal naturally rich lake, possibily because of an interference of metals with the chemical communication system of prey organisms. Zooplankton population declines could lead to a variation of the overall grazing rate, and to an increase in the abundance of phytoplankton which are typically grazed by zooplankton. This sort of top-down ecosystem disturbance could impact interactions at lower trophic levels and contribute to eutrophication (Sutor et al. 2001; Thorp \& Covich 1991).

\section{ACNOWLEDGMENTS}

The authors are thankful to A. Varallo, A. Ferrauto and R. Ambrosini for assistance, and to two anonymous referees for useful suggestions. We are also very grateful to CNE-ISE Institute of Ecosystem Study researchers for data of metal concentrations in MG Lake and for their constructive suggestions.

\section{REFERENCES}

Benjamini, Y. \& Y. Hochberg. 1995. Controlling the False Discovery Rate: a practical and powerful approach to multiple testing. Journal of the Royal Statistic Society B, 57: 289-300

Beyers, D.W. \& M.S. Farmer. 2001 Effects of copper on olfaction of Colorado pikeminnow. Environ. Toxicol. Chem., 20(4): 907-912.

Black, A.R. 1993. Predator-induced phenotypic plasticity in Daphnia pulex: life history and morphological responses to Notonecta and Chaoborus. Limnol. Oceanogr., 38: 986996.

Black, A.R. \& S.I. Dodson. 1990. Demographic costs of Chaoborus-induced phenotypic plasticity in Daphnia pulex. Oecologia, 83: 117-122.

Boeing, W.J., B. Wissel \& C.W. Ramcharan. 2005. Costs and benefits of Daphnia defense against Chaoborus in nature. Can. J. Fish. aquat. Sci., 62(6): 1286-1294.

Caramujo, M.J., M.C. Crispim \& M.J. Boavida. 1997. Assessment of the importance of fish predation versus copepod predation on life history traits of Daphnia hyalina. Hydrobiologia, 360: 243-252.

Caramujo, M.J. \& M.J. Boavida. 2000. Induction and costs of tail spine elongation in Daphnia hyalina $\times$ galeata: reduction of susceptibility to copepod predation. Freshwat. Biol., 45: 413-423.
Cousyn, C., L. De Meester, J.K. Colbourne, L. Brendonck, D. Verschuren \& F. Volckaert. 2001. Rapid, local adaptation of zooplankton behavior to changes in predation pressure in the absence of neutral genetic changes. Proc. Natl. Acad. Sci. U S.A., 98(11): 6256-6260.

Dahms, H.U. \& C.H. Fernando. 1993. Redescription of Mesocyclops leuckarti (Copepoda, Cyclopoida), including a study of its naupliar development. Int. Rev. Ges. Hydrobiol., 78(4): 589-609.

Deng, H.W. 1996. Environmental and genetic control of sexual reproduction in Daphnia. Heredity, 76: 449-458.

Dussart, B.H. \& D. Defaye. 1995. Introduction to the Copepoda. SPB Academic, The Hague.

Garcia, L.V. 2003. Controlling the false discovery rate in ecological research. Trends Ecol. Evol., 18: 553-554.

Gliwicz, Z.M., P. Dawidowicz \& P. Maszczyk. 2006. Lowdensity anti-predation refuge in Daphnia and Chaoborus? Arch. Hydrobiol., 167: 101-114.

Gyllström, M. \& L.A. Hansson. 2004. Dormancy in freshwater zooplankton: Induction, termination and the importance of benthic-pelagic coupling. Aquat. Sci., 66: 274-295.

Hanazato, T. 1990. A comparison between predation effects on zooplankton communities by Neomysis and Chaoborus. Hydrobiologia, 198: 33-40.

Hanazato, T. \& M. Yasuno. 1989. Zooplankton community structure driven by vertebrate and invertebrate predators. Oecologia, 81: 450-458.

Hansen, J.A., J.D. Rose, R.A. Jenkins, K.G. Gerow \& H.L. Bergman. 1999. Chinook salmon (Oncorhynchus tshawytscha) and rainbow trout (Oncorhynchus mykiss) exposed to copper: Neurophysiological and histological effects on the olfactory system. Environ. Toxicol. Chem., 18: 1979-1991.

Hunter, K. \& G. Pyle. 2004. Morphological responses of Daphnia pulex to Chaoborus americanus kairomone in the presence and absence of metals. Environ. Toxicol. Chem., 23(5): 1311-1316.

Kira, T. 1993. Major environmental problems in world lakes. In: De Bernardi R., R. Pagnotta \& A. Pugnetti (Eds), Strategies for Lake Ecosystems Beyond 2000. Mem. Ist. ital. Idrobiol., 52: 1-7.

Krieger, J. \& H. Breer. 1999. Olfactory reception in invertebrates. Science, 286: 720-723.

Korpelainen, H. 1992. Lowered female reproductive effort as an indicator for increased male production and sexuality in Daphnia (Crustacea: Cladocera). Invertebrate Reproduction and Development, 22: 281-290.

Innes, D.J. \& D.R. Singleton. 2000. Variation in allocation to sexual and asexual reproduction among clones of cyclically parthenogenetic Daphnia pulex (Crustacea: Cladocera). Biological Journal of the Linnean Society, 71(4): 771-787.

Jeyasingh, P.D. \& L.J. Weider. 2005. Phosphorus availability mediates plasticity in life-history traits and predator-prey interactions in Daphnia. Ecology Letters, 8: 1021-1028.

Liljendahl-Nurminen, A., J. Horppila, P. Eloranta, T. Malinen \& L. Uusitalo. 2002. The seasonal dynamics and distribution of Chaoborus flavicans larvae in adjacent lake basins of different morphometry and degree of eutrophication. Freshwat. Biol., 47: 1283-1295.

Lynch, M. 1980. The evolution of cladoceran life histories. $Q$. Rev. Biol., 55: 23-42.

McQueen, D.J., C.W. Ramcharan, E. Demers, N.D. Yan, L.M. Conforti \& A.Pérez-Fuentaja. 1999. Chaoborus behavioural responses to changes in fish density. Arch. Hydrobiol., 145: 165-179.

Margaritora, F. 1983. Cladoceri (Crustacea: Cladocera) Guide per il riconoscimento delle specie animali delle acque interne italiane. Consiglio Nazionale delle Ricerche $\mathrm{AQ} / 1 / 197$, no. 22. Stamperia Valdonega, Verona. 
Mort, M. 1986. Chaoborus predation and the function of phenotypic variation in Daphnia. Hydrobiologia, 133: 39-44.

Mumm, H. 1997. Effects of competitors and Chaoborus predation on the cladocerans of a eutrophic lake: an enclosure study. Hydrobiologia, 360: 253-264.

Mumm, H. \& A.F. Sell. 1995. Estimating the impact of Chaoborus predation on zooplankton: a new design for in situ enclosures studies. Arch. Hydrobiol., 134: 195-206.

Nakagawa, S. 2004. A farewell to Bonferroni: the problems of low statistical power and publication bias. Behav. Ecol., 15: 1044-1045.

Neill, W.E. 1981. Impact of Chaoborus predation upon the structure and dynamics of a crustacean zooplankton community. Oecologia, 48: 164-177.

Nicholls, K.H. \& C. Tudorancea. 2001. Species-level and community-level data analyses reveal spatial differences and temporal change in the crustacean zooplankton of a large Canadian Lake (Lake Simcoe, Ontario). J. Limnol., 60(2): 155-170.

Nielsen, D.L., F.J. Smith, T.J. Hillman \& R.J. Shiel. 2000. Impact of water regime and fish predation on zooplankton resting egg production and emergence. J. Plankton Res., 22(3): 433-446.

Nogrady, T., R.L. Wallace \& T.W. Snell. 1993. Rotifera. SPB Academic, The Hague.

Parejko, K. 1991. Predation by chaoborids on typical and spined Daphnia pulex. Freshwat. Biol., 25: 211-217.

Pastorok, R.A. 1981. Prey vulnerability and size selection by Chaoborus larvae. Ecology, 62: 1311-1324.

Ponyi, J.E. \& N.P. Zankai. 1982. Population dynamics, biomass and biomass production of Eudiaptomus gracilis (G. O. SARS) in two water areas of different trophic state of L. Balaton (Hungary). Acta Hydrochimica et Hydrobiologica, 10: 597-610.

Repka, S., M. Walls \& M. Ketola. 1995. Neck spine protects Daphnia pulex from predation by Chaoborus, but individuals with longer tail spine are at a greater risk. $J$. Plankton Res., 17: 393-403.

Riccardi, N., G. Giussani \& L. Lagorio. 2002. Morphological variation and life history changes of a Daphnia hyalina population exposed to Chaoborus flavicans larvae predation (L. Candia, Northern Italy). J. Limnol., 61(1): 41-48.

Riessen, H.P. 1992. Cost-benefit model for the induction of an antipredator defense. Am. Nat., 140: 349-362.

Ruttner-Kolisko, A. 1974. Planktonic rotifers. Biology and Taxonomy. Die Binnengewasser (Supplement), 26: 1-146

Sæther, O.A. 1997. Diptera Chaoboridae, Phantom midges. In: A. Nilsson (Ed.), Aquatic Insects of North Europe. Apollo Books, Stenstrup, 2: 149-161.

Schwenk, K. \& P. Spaak. 1997. Ecology and genetics of interspecific hybridization in Daphnia. In: Streit, B., T. Städler \& C. Lively (Eds.), Ecology and Evolution of Freshwater Animals. Birkhäuser Verlag, Basel: 199-229.

Received: July 2008

Accepted: December 2008
Sell, A.F. 2000. Morphological defenses induced in situ by the invertebrate predator Chaoborus: comparison of responses between Daphnia pulex and D. rosea. Oecologia, 125: $150-160$.

Sell, A.F. 2006. A trophic cascade with Chaoborus: population dynamics of ex-ephippial generations of Daphnia. Archiv. Hydrobiol., 167: 115-134.

Spaak, P. 1995. Sexual reproduction in Daphnia: interspecific differences in a hybrid species complex. Oecologia, 104: 501-507.

Spitze, K. 1992. Predator-mediated plasticity of prey life history and morphology: Chaoborus americanus predation on Daphnia pulex. Am. Nat., 139: 229-247.

Stibor, H. 1992. Predator induced life-history shifts in a freshwater cladoceran. Oecologia, 92: 162-165.

Stross, R. 1971. Photoperiodism and diapause in Daphnia: a strategy for all seasons. Trans Am. Micro. Soc., 90: 110-112.

Sutor, M., C. Ramcharan \& R.G. Downer. 2001. Predation effects of two densities of fourth-instar Chaoborus trivittatus on a freshwater zooplankton assemblage. Hydrobiologia, 464: 121-131.

Swift, M.C. 1992. Prey capture by the fourth larval instars of Chaoborus cristallinus. Limnol. Oceanogr., 37: 14-24.

Thorp, J.H. \& A.P. Covich. 1991. An overview of freshwater habitats. In: Thorp, J.H. \& A.P. Covich (Eds), Ecology and Classification of North American Freshwater Invertebrates. Harcourt Brace Jovanovich, N.Y.: 17-36.

Tollrian, R. \& S.I. Dodson. 1999. Inducible defences in cladocera: constraints, costs, and multipredator environments. In: Tollrian, R. \& C.D. Harvell (Eds), The ecology and evolution of inducible defenses. Princeton University Press, Princeton, N.J.: 177-202.

Tollrian, R. \& E. von Elert. 1994. Enrichment and purification of Chaoborus kairomone from water: further steps towards its chemical characterization. Limnol. Oceanogr., 39: 788-796.

Vanni, M.J. 1988. Freshwater zooplankton community structure: introduction of large invertebrate predators and large herbivores to a small-species community. Can. J. Fish. aquat. Sci., 45: 1758-1770.

Van de Meutter, F., R. Stoks \& L. De Meester. 2005. Spatial avoidance of littoral and pelagic invertebrate predators by Daphnia. Oecologia, 142: 489-499.

Verhoeven, K.J.F., K.L. Simonsen \& L.M. McIntyre. 2005. Implementing false discovery rate control: increase your power. Oikos, 108: 643-647.

von Ende, C.N. 1978. Regional coexistence of four Chaoborus species. Verh. int. Ver. Limnol., 20: 2630-2633.

Wellborn, G.A., D.K. Skelly \& E.E. Werner. 1996. Mechanisms creating community structure across a freshwater habitat gradient. Ann. Rev. Ecol. Syst., 27: 337-363. 